\title{
Diagnóstico de HPV Anal em Mulheres com NIC: Prevenção de Câncer do Ânus?
}

\section{Anal HPV Diagnosis in Women with NIC: Anal Cancer Prevention?}

\author{
ALICE CAPOBIANGO ${ }^{1}$; AGNALDOLOPES DASILVAFILHO²; TARCIZOAFONSO NUNES ${ }^{3}$
}

\author{
${ }^{1}$ Mestra em Cirurgia pela UFMG, Coordenadora do Serviço de Coloproctologia do Hospital Luxemburgo, Pesquisadora \\ Associada do NUPAD; ${ }^{2}$ Prof. Adjunto-Doutor do Departamento de Ginecologia e Obstetrícia da FMUFMG; ${ }^{3}$ Prof. \\ Associado do Departamento de Cirurgia da FMUFMG.
}

\begin{abstract}
CAPOBIANGO A; SILVA FILHO, AL; NUNES TA. Diagnóstico de HPV Anal em Mulheres com NIC: Prevenção de Câncer do Ânus? Rev bras Coloproct, 2009;29(4): 443-450

RESUMO: Os objetivos deste estudo foram avaliar a frequência de HPV anal em pacientes com neoplasia intraepitelial cervical (NIC), verificar a concordância entre os subtipos encontrados nos dois locais e investigar os fatores que influenciaram a ocorrência de HPV anal em mulheres com NIC sem evidências clínicas de imunodepressão. Foram avaliadas 52 mulheres com idades entre 16 e 72 anos e diagnóstico de neoplasia intraepitelial cervical graus I, II e III. A identificação do DNA (ácido desoxirribonucleico) do HPV e de sete subtipos dos vírus foi realizada por meio da reação em cadeia da polimerase (PCR) em material colhido no ânus e colo uterino. Foram pesquisados fatores que poderiam contribuir para a infecção anal, como paridade, número de parceiros, tabagismo, manipulação e coito anal e o tipo de doença ginecológica. Das 52 mulheres, foi diagnosticado HPV na região anal em 25 (48\%), das quais 23 (44\%) também apresentavam HPV no colo uterino - resultado significativo para existência do HPV em portadoras de NIC. Em 16 (31\%) o HPV foi diagnosticado somente no colo uterino e em 11 (21\%) não foi identificado em colo ou ânus. Houve associação significativa nas variáveis paridade $(p=0,02)$ e número de parceiros $(p=0,04)$. Concluiu-se que: as mulheres com HPV genital têm mais probabilidade de serem acometidas por HPV anal; não há concordância unânime entre os subtipos do HPV do colo do útero e do ânus e a paridade e o número de parceiros contribuem para aumentar a incidência de HPV anal nas mulheres sem imunodeficiência e com HPV cervical.
\end{abstract}

Descritores: Papilomavírus humano (HPV). Doenças do ânus/virologia. Colo uterino. Reação em cadeia da polimerase (PCR). Neoplasia intraepitelial cervical (NIC).

\section{INTRODUÇÃO}

A infecção pelo papilomavírus humano (HPV) acomete pessoas de qualquer idade, embora seja mais comum em jovens, provavelmente devido a mais atividade sexual nesse período. Sua associação com o vírus da imunodeficiência adquirida pode atingir $62 \%$ dos $\operatorname{casos}^{1}$.

A associação entre HPV de alto risco e neoplasia de ânus em homens e mulheres com imunodeficiência ou imunossupressão está confirmada e as medidas relacionadas à vigilância estão padro- nizadas $^{1-3}$. Em pacientes sem imunodeficiências, entretanto, essa associação ainda não está esclarecida, o que pode contribuir para a falta de normas adequadas para diagnosticar o HPV e prevenir o câncer de ânus s- $^{4-}$ 6. A frequência do câncer de ânus antes considerada baixa encontra-se atualmente em elevação considerável, principalmente o carcinoma de células escamosas (CCE). Concomitantemente a esse fato, tem sido constatado o aumento das infecções anogenitais por papilomavírus humano, que acomete $20 \%$ da população mundial sexualmente ativa ${ }^{7}$. A relação causal entre esse vírus e o câncer do colo do útero e do ânus

Trabalho realizado no Programa de Pós-Graduação em Ciências Aplicadas à Cirurgia e à Oftalmologia da Faculdade de Medicina da Universidade Federal de Minas Gerais. 
está estabelecida ${ }^{1,8,9}$. Esses fatos têm motivado a inclusão dessa doença como sexualmente transmissível, o que justifica a necessidade de adoção de medidas de vigilância nas clínicas de doenças sexuais, ginecológicas e urológicas $^{10,11}$. O câncer de ânus, quando diagnosticado no estágio inicial, torna possível a cura sem necessidade de tratamento cirúrgico, mas no estágio avançado é necessária a amputação abdominoperineal.

Preocupados com possíveis neoplasias anais, alguns ginecologistas têm encaminhado pacientes com HPV genital para pesquisar infecção anal. Essa conduta, entretanto, ainda é pouco empregada nas pacientes sem queixas anais, devido às dúvidas sobre a validade do exame proctológico. Os dados disponíveis na literatura a respeito da concomitância de infecções nos diferentes sítios da região anogenital em mulheres HIV positivo são escassos e mais ainda em pacientes sem imunodeficiências, o que impossibilita responder a esta questão com segurança ${ }^{4}$. Diante desses questionamentos, esta pesquisa se propôs a: avaliar se mulheres clinicamente imunocompetentes, sem evidências clínicas de doença anal e com NIC têm mais probabilidade de contaminação anal por esses vírus; verificar se há concordância entre os subtipos de HPV encontrados nas regiões genital e anal; e identificar fatores que possam influenciar a ocorrência de HPV anal.

\section{PACIENTES E MÉTODO}

Foi realizado estudo prospectivo sobre a presença de HPV anal em mulheres atendidas no Hospital Mário Pena e Ambulatório Carlos Chagas do Hospital das Clínicas da UFMG, no período de janeiro a dezembro de 2007. O projeto da pesquisa foi aprovado pelo Comitê de Ética em Pesquisa (COEP) da UFMG, parecer $n^{\circ}$ ETIC 394/07, e Comitê de Ética em Pesquisa da Fundação Mário Pena, parecer no 17/2005. O estudo incluiu 52 mulheres com idades entre 16 e 72 anos (mediana de $39 \pm 16,0$ ), sendo nove $(17,3 \%)$ negras, $12(23,0 \%)$ pardas e $31(59,7 \%)$ brancas. Elas foram avaliadas por meio de anamnese e exame físico, incluindo exame ginecológico e proctológico, com a participação da autora da pesquisa em todos os casos. Foram incluídas as pacientes com diagnóstico prévio ou atual de neoplasia intraepitelial cervical (NIC) graus I, II e III e ausência de sinais e sintomas compatíveis com HPV anal. Foram excluídas as que tinham as seguintes características: prurido, verrugas e/ou lesões com evidência de HPV à inspeção anal; uso de imunossupressores; diagnóstico de imunodeficiência de qualquer etiologia; sensibilidade à lidocaína; gestantes; procedimentos cirúrgicos em ânus nos três meses anteriores e recusa em participar da pesquisa.

$\mathrm{Na}$ anamnese foram enfatizadas as informações sobre os possíveis fatores de risco para contrair a infecção, tais como: tabagismo, paridade, início das atividades sexuais, número de parceiros, coito e/ou manipulação anal e doença ginecológica, ou seja, queixas e hábitos que pudessem estar relacionados com a infecção anal por HPV.

$\mathrm{O}$ exame ginecológico e o proctológico foram realizados na mesma consulta. Depois da inspeção e colocação do espéculo vaginal, coletou-se material em colo uterino, empregando-se escova de citologia vaginal. Em seguida, procedeu-se ao exame proctológico, iniciando-se com a inspeção anal, coleta de material com escova de citologia vaginal e anuscopia com magnificação de imagens, orientada pela ginecologia. O material obtido nesses exames foi acondicionado em solução de cloreto de sódio $0,9 \%$ para pesquisa do HPV por meio da técnica de reação em cadeia da polimerase (PCR) e se o vírus correspondia aos subtipos $6,11,16$, $18,31,33,35$.

Durante o exame ginecológico e proctológico associados à magnificação de imagens, foram colhidos espécimes de lesões macroscópicas, para exame anatomopatológico pelo método de hematoxilinaeosina.

Variáveis estudadas e testes estatísticos

Frequência de HPV anal na presença de neoplasia intraepitelial cervical, expressa em porcentagem pelo teste do qui-quadrado;

frequência e subtipos de HPV anal em mulheres com NIC e sem evidências de doença anal expressa em porcentagem e teste do qui-quadrado;

influência dos fatores de risco para contrair a infecção por meio de regressão logística (análise bivariada).

Todos os dados obtidos na pesquisa foram codificados e digitados em banco de dados no programa Statistical Package for Social Sciences (SPSS) para Windows versão 16.0 (SPSS Inc., Chicago, IL, EUA), que desenvolveu os cálculos. A frequência dos resultados foi analisada, em termos probabilísticos, por meio do teste do qui-quadrado, de acordo com o método 
descrito por Soares e Siqueira (1999) ${ }^{12}$, uma vez que as variáveis são dicotômicas e não-paramétricas. Fixou-se o nível de significância em $p<0,05$, para aceitar as diferenças entre os grupos do experimento. O número de pacientes avaliadas representa uma amostra considerada significativa para o estudo da prevalência do HPV anal em mulheres com infecção em colo de útero.

\section{RESULTADOS}

Presença de HPV anal em mulheres com infecção genital por esse vírus

Das 52 mulheres, o HPV foi diagnosticado concomitantemente na região anal e colo uterino em 23 (44\%). Em 16 (31\%), apenas no colo uterino; em duas (4\%), apenas no ânus; e em 11(21\%), em nenhuma das duas regiões. Houve, portanto, associação significativa entre o HPV anal e no colo uterino $(\mathrm{p}=0,008)$. O risco relativo de HPV anal é 3,83 vezes mais alto nas pacientes com essa infecção genital em comparação àquelas sem essa infecção (Figura 1).

Associação da frequência e subtipos de HPV anal e no colo uterino em mulheres com NIC e sem evidências de doença anal

Das 25 pacientes com HPV no ânus, foram identificados os subtipos virais em seis, sendo o mais prevalente o HPV 6. Dessas seis, em três foram iden- tificados dois subtipos em cada (6 e 35, 6 e 31, 31 e 35). Das 39 mulheres com HPV no colo uterino, o subtipo do vírus foi identificado em 18 , sendo o mais prevalente o subtipo 16 , seguido dos de números 6,31 , 33, 35 e 18. Dos sete subtipos de vírus pesquisados, foi verificada a concordância nas duas regiões em quatro mulheres $(17,39 \%)$, sendo eles o 6, 31, 33 e 35 . Não houve diferença significante quanto à coocorrência dos subtipos virais nas mulheres, nas quais foi diagnosticado o HPV nos dois locais (Figura 2, Tabelas 1 e 2).

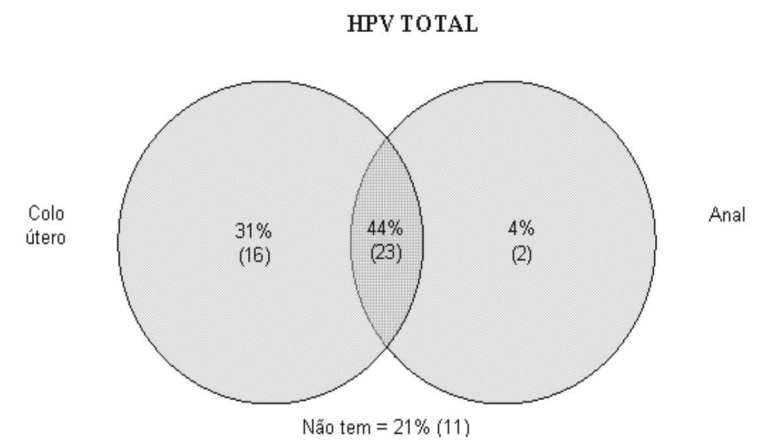

Figura 1 - Pesquisa do HPV na região anal e colo uterino em mulheres com NIC $(n=52)$.

HPV - Papilomavírus humano, NIC - Neoplasia intraepitelial cervical.

Associação HPV anal vs. HPV colo uterino: $p=0,008$ (teste quiquadrado).

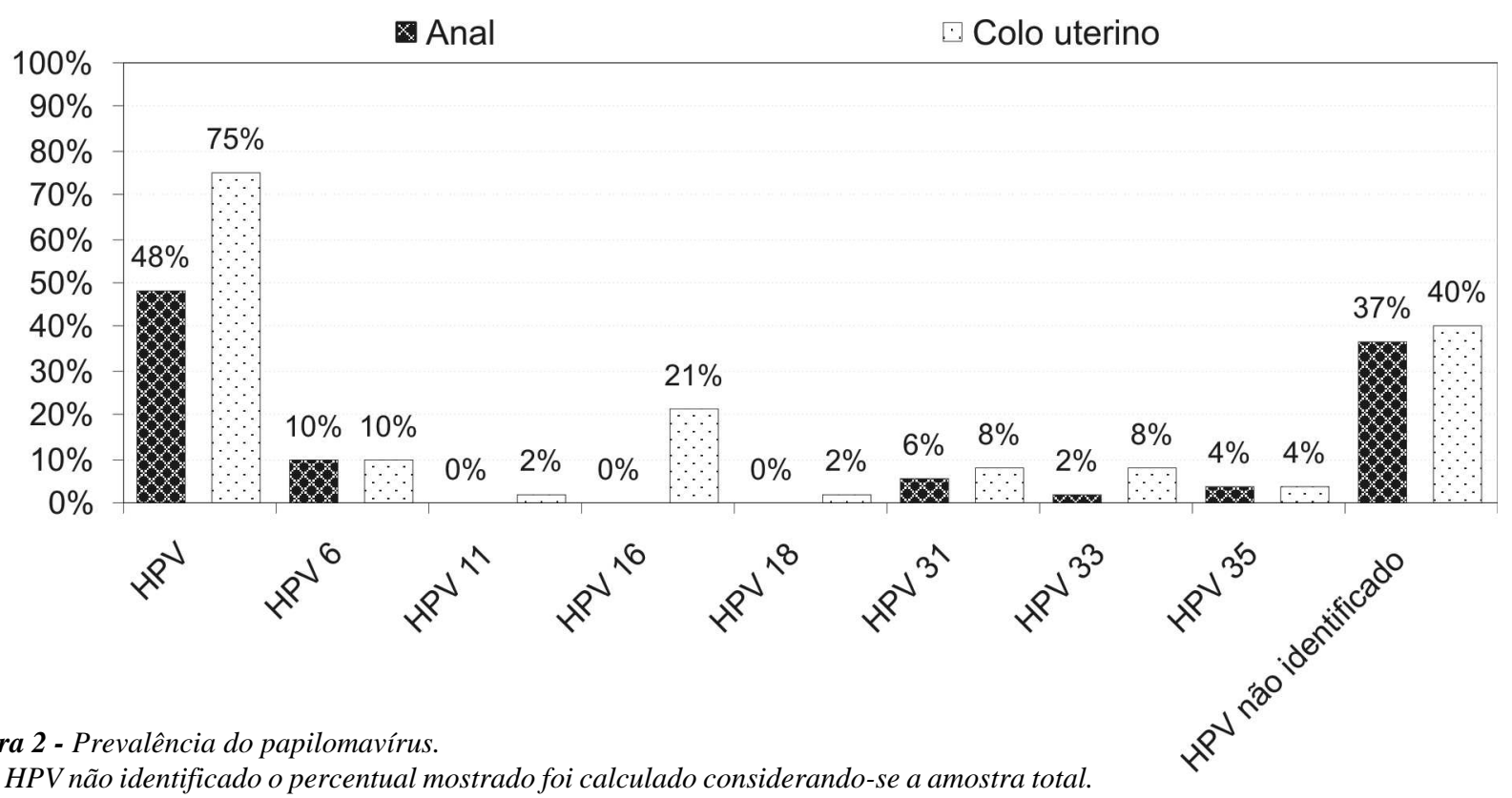

Para HPV não identificado o percentual mostrado foi calculado considerando-se a amostra total. 
Tabela 1 - Coocorrência dos subtipos de HPV na região anal e colo uterino em mulheres com NIC.

\begin{tabular}{c|lcccccccc}
\hline & \multicolumn{8}{c}{ COLO UTERINO } \\
\cline { 3 - 9 } \multicolumn{1}{c}{ Subtipo } & HPV & HPV 6 & HPV 11 & HPV 16 & HPV 18 & HPV 31 & HPV 33 HPV 35 \\
\hline \multirow{3}{*}{} & HPV & $44 \%(23)$ & $6 \%(3)$ & - & $12 \%(6)$ & $2 \%(1)$ & $2 \%(1)$ & $6 \%(3)$ & $4 \%(2)$ \\
& HPV 6 & $10 \%(5)$ & $\mathbf{2 \% ( 1 )}$ & - & $2 \%(1)$ & - & - & - & $2 \%(1)$ \\
& HPV 11 & - & - & - & - & - & - & - & - \\
& HPV 16 & - & - & - & - & - & - & - & - \\
& HPV 18 & - & - & - & - & - & - & - & - \\
& HPV 31 & $6 \%(3)$ & - & - & $2 \%(1)$ & $2 \%(1)$ & $\mathbf{2 \%}(\mathbf{1})$ & - & $2 \%(1)$ \\
& HPV 33 & $2 \%(1)$ & - & - & - & - & - & $\mathbf{2 \%}(\mathbf{1})$ & $0 \%(0)$ \\
& HPV 35 & $4 \%(2)$ & $2 \%(1)$ & - & $2 \%(1)$ & $2 \%(1)$ & - & - & $\mathbf{2 \%}(\mathbf{1})$ \\
\hline
\end{tabular}

*O valor fora dos parênteses mostra o percentual de casos que apresentam os subtipos do vírus de maneira conjunta. ** $O$ valor dentro dos parênteses indica o número de coocorrências na amostra .

Fatores que influenciaram a ocorrência de HPV anal em mulheres com NIC

As pacientes tiveram, em média, dois parceiros sexuais. A paridade variou entre nulípara e 10 partos (média de 2,1 $\pm 2,0$ partos); oito $(15,4 \%)$ eram tabagistas e $16(30,8 \%)$ usavam contraceptivos hormonais. A prática de coito anal foi confirmada por $18(34,6 \%)$ mulheres e manipulação anal por 19 (36,5\%). O grau de neoplasia ocorreu na frequência seguinte: NIC I $(67,3 \%)$, NIC III $(21,2 \%)$ e NIC II $(11,5 \%)$.

Entre os fatores pesquisados, houve associação significativa nas variáveis paridade $(\mathrm{p}=0,02)$ e número de parceiros $(\mathrm{p}=0,04)$, ou seja, alto número de filhos e de parceiros aumenta a chance de a mulher contrair o papilomavírus humano anal. Nas demais variáveis, os resultados não foram significantes (Tabela 3).

Tabela 2 - Coocorrências entre subtipos do HPV em mulheres com NIC.

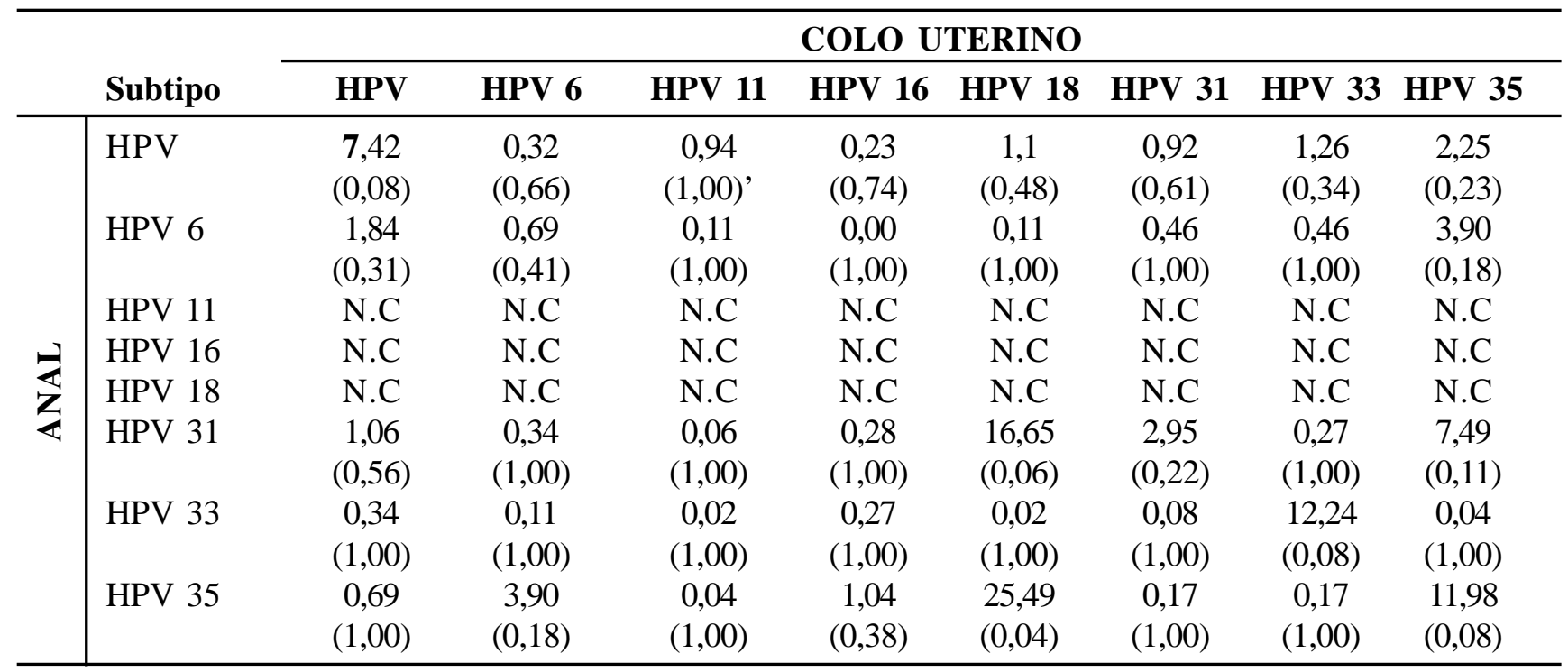

A associação entre subtipos do HPV foi feita pelo teste do qui-quadrado e significância exata. O valor fora dos parênteses mostra o valor da estatística qui-quadrado para as coocorrências na amostra. $O$ valor dentro dos parênteses indica a significância exata da associação. $N C=$ não calculado. 
Tabela 3 - Variáveis estudadas na infecção de HPV na região anal em mulheres com NIC.

\begin{tabular}{|c|c|c|c|c|c|c|c|c|c|}
\hline \multirow{3}{*}{$\begin{array}{l}\text { Variáveis } \\
\text { Tabagismo }\end{array}$} & \multirow{3}{*}{$\begin{array}{c}\text { Categorias } \\
\text { Não }\end{array}$} & \multicolumn{4}{|c|}{ HPV Anal } & \multirow[t]{3}{*}{$\mathbf{p}$} & \multirow{3}{*}{$\begin{array}{l}\mathbf{O R} \\
1,00\end{array}$} & \multicolumn{2}{|c|}{ Intervalo } \\
\hline & & \multicolumn{2}{|c|}{ Ausente } & \multicolumn{2}{|c|}{ Presente } & & & \multirow[t]{2}{*}{$\mathbf{L I}$} & \multirow[t]{2}{*}{$\mathbf{L S}$} \\
\hline & & $93 \%$ & $( \pm 10 \%)$ & $76 \%$ & $( \pm 17 \%)$ & & & & \\
\hline & Sim & $7 \%$ & $( \pm 10 \%)$ & $24 \%$ & $( \pm 17 \%)$ & 0,12 & 3,95 & 0,72 & 21,78 \\
\hline Paridade & & 1,52 & $( \pm 0,38)$ & 2,76 & $( \pm 0,86)$ & $\mathbf{0 , 0 2}$ & 1,72 & 1,09 & 2,71 \\
\hline Início atividades sexuais & & 19,41 & $( \pm 1,83)$ & 17,12 & $( \pm 1,43)$ & 0,07 & 0,88 & 0,76 & 1,01 \\
\hline Número de parceiros & & 2,22 & $( \pm 0,49)$ & 3,60 & $( \pm 1,06)$ & 0,04 & 1,47 & 1,01 & 2,13 \\
\hline \multirow[t]{2}{*}{ Manipulação anal } & Não & $56 \%$ & $( \pm 19 \%)$ & $72 \%$ & $( \pm 18 \%)$ & & 1,00 & & \\
\hline & Sim & $44 \%$ & $( \pm 19 \%)$ & $28 \%$ & $( \pm 18 \%)$ & 0,22 & 0,49 & 0,15 & 1,55 \\
\hline \multirow[t]{2}{*}{ Coito anal } & Não & $56 \%$ & $( \pm 19 \%)$ & $76 \%$ & $( \pm 17 \%)$ & & 1,00 & & \\
\hline & Sim & $44 \%$ & $( \pm 19 \%)$ & $24 \%$ & $( \pm 17 \%)$ & 0,13 & 0,39 & 0,12 & 1,30 \\
\hline \multirow{5}{*}{$\begin{array}{l}\text { Coito anal e/ou } \\
\text { manipulação anal } \\
\text { Doença ginecológica }\end{array}$} & Não & $56 \%$ & $( \pm 19 \%)$ & $72 \%$ & $( \pm 18 \%)$ & & 1,00 & & \\
\hline & Sim & $44 \%$ & $( \pm 19 \%)$ & $28 \%$ & $( \pm 18 \%)$ & 0,22 & 0,49 & 0,15 & 1,55 \\
\hline & NIC 1 & $81 \%$ & $( \pm 15 \%)$ & $52 \%$ & $( \pm 20 \%)$ & 0,05 & 0,22 & 0,05 & 0,99 \\
\hline & NIC 2 & $7 \%$ & $( \pm 10 \%)$ & $16 \%$ & $( \pm 14 \%)$ & 0,79 & 0,75 & 0,09 & 6,47 \\
\hline & NIC 3 & $11 \%$ & $( \pm 12 \%)$ & $32 \%$ & $( \pm 18 \%)$ & 0,09 & 1,00 & & \\
\hline
\end{tabular}

HPV-Papilomavírus humano, NIC-Neoplasia intraepitelial cervical.

OR: odds ratio; LI: limite inferior de confiança (95\%); LS: limite superior de confiança (95\%); p: significância (valor p) da relação.

\section{DISCUSSÃO}

Sabe-se que o fato de haver uma área do epitélio anogenital infectada pelo HPV facilita a dispersão do vírus para as áreas adjacentes ${ }^{13}$. Diante disso, considerou-se pertinente a realização da pesquisa em número adequado de pacientes, no sentido de possibilitar resposta concreta sobre o tema.

Entre todos os métodos descritos na literatura, considera-se que a PCR é o mais adequado para o diagnóstico etiológico do HPV ${ }^{14-16}$, razão pela qual ele foi empregado neste estudo. $\mathrm{O}$ exame diagnosticou primeiramente se o vírus estava presente no colo do útero e região anal e, em caso afirmativo, se eram dos subtipos $6,11,16,18,31,33$ ou 35 ou diferente deles.

Das 52 mulheres avaliadas, em 23 (44\%) foi diagnosticado HPV na região anal e no colo uterino, cuja associação foi significante ( $\mathrm{p}=0,008)$. Em 16 (31\%), o HPV foi encontrado somente no colo uterino e duas (4\%) o tinham apenas no ânus. Não foi encontrado na literatura estudo relacionado especificamente com esses resultados, para efeito de comparação. Em 11 (21\%) pacientes não foi encontrado HPV no colo uterino nem no ânus e para esse resultado foram encontradas justificativas na literatura. De acordo com Sobti ${ }^{17}$, o diagnóstico do HPV por PCR pode ser variável em até
$85 \%$ nos casos de câncer cervical invasivo e 63,6\% nas alterações mais simples.

Tachezy et al. ${ }^{9}$ correlacionaram histologia e detecção do HPV por PCR em material de pacientes com tumores em canal anal e nele encontrou fragmentos de lesões morfológicas típicas de infecção por HPV, sem conseguir diagnosticar o DNA do vírus pela PCR. Esses casos foram considerados burned out, de acordo com a classificação de tumores do sistema digestivo da $\mathrm{WHO}^{18}$. Calore et al. ${ }^{19}$ e Nadal et al. ${ }^{2}$ preconizaram que as técnicas de detecção molecular do HPV podem diagnosticar o vírus em até $75 \%$ dos casos e afirmaram que a ausência do vírus por esse método não permite descartar o diagnóstico de doença viral.

No presente trabalho, ficou demonstrado que a probabilidade de as mulheres com HPV ginecológico terem o vírus no ânus é 3,83 vezes mais alta do que na ausência de infecção no colo do útero, sendo mais baixa que em mulheres HIV+. Nestas pacientes, a concomitância ocorreu em $68 \%$ dos casos, sendo mais elevado o número de subtipos virais e relativamente raro o subtipo $16^{4}$.

A pesquisa dos subtipos virais nas regiões genital e anal encontrou concordância baixa, sem significância pelo teste do qui-quadrado. Uma hipótese para explicar esse fato pode estar relacionada com o tropismo do vírus. Assim como existem subtipos de ví- 
rus diferentes que acometem pele, mucosa e outros tecidos, o mesmo pode ocorrer nas regiões genitais e anais. Variações também podem ser encontradas devido a diferenças entre faixas etárias e até por variações geográficas. É necessário, entretanto, pesquisa com mais pacientes para se confirmar essa hipótese.

Em estudo sobre a epidemiologia do HPV direcionado para a dinâmica da transmissão sexual em populações da África, América, Europa e Ásia, foi encontrada, em pacientes com SIDA, mais concordância entre os subtipos detectados em colo uterino, vagina e ânus, havendo mais concordância entre colo uterino e vagina $^{20}$.

Quanto aos fatores considerados determinantes da vigência do papilomavírus humano no ânus, os resultados foram significantes somente quanto à paridade e ao número de parceiros. Esperava-se que o coito e a manipulação anal fossem importantes para a infecção do HPV anal, como relatado na literatu$\mathrm{ra}^{20-22}$. Essa divergência de resultados pode ter como explicação o fato de as pacientes da presente pesquisa se sentirem inibidas em responder sobre sua intimidade sexual em ambiente com pouca privacidade, como ocorre em ambulatório usado também para ensino.

O tamanho da amostra também pode ter contribuído para essa discrepância de resultados. Inicialmente, pensou-se que seria rápida e fácil a realização de exame proctológico em muitas pacientes, uma vez que a incidência de HPV genital é elevada. Apesar de ter sido realizado trabalho de convencimento com vários ginecologistas, houve dificuldade de obtenção de pacientes para o estudo. Deve ser salientado que essa conduta ainda não faz parte da rotina e há questionamento dos profissionais da área sobre a necessidade do exame proctológico em pacientes sem sintomas anais. Vale enfatizar, entretanto, que a amostra foi considerada suficiente para a análise geral da infecção por HPV.

O colposcópio tem sido empregado para diagnosticar áreas sugestivas de alterações por HPV no canal anal e região perianal ${ }^{13,23}$. Jay et al. ${ }^{24}$ utilizaram a magnificação de imagens e os parâmetros usados na colposcopia ginecológica em canal anal de 152 homens nos quais realizaram 358 biópsias. Concluíram que as imagens encontradas nos diferentes graus de neoplasias intraepiteliais evidenciadas eram similares àquelas descritas em colo uterino. As alterações passíveis de serem encontradas ainda não fo- ram padronizadas, como o é na ginecologia. Os padrões empregados no exame ginecológico têm sido usados, quando possível, bem como biópsia das áreas suspeitas para confirmação do diagnóstico e pesquisa de possíveis neoplasias.

Com o objetivo de se adquirir experiência com método novo em coloproctologia, o colposcópio foi empregado no exame da região anal de todas as pacientes, em seguida ao exame ginecológico, com supervisão e orientação da ginecologia. Em apenas um caso identificaram-se alterações compatíveis com HPV, cuja biópsia mostrou tratar-se de lesão compatível com papilomavírus, porém sem atipia celular. Foram detectados, nessa paciente, o vírus 16 no colo uterino e HPV no ânus, entretanto, diferente dos sete subtipos investigados.

O tipo mais comum do câncer de ânus, o carcinoma de células escamosas, surge em áreas de neoplasias intraepiteliais de alto grau em canal anal, como consequência de infecção crônica pelo papilomavírus humano e parece ter relação com alta carga do vírus na infecção ${ }^{25}$. Mulheres com história de neoplasia em colo uterino são consideradas, epidemiologicamente, em risco de desenvolver câncer de ânus?.

Diante do novo conceito de doença sexualmente transmissível para o câncer anal e do resultado significativo obtido a respeito da prevalência de HPV em ânus nas pacientes com esse vírus em colo uterino, fazem-se necessárias campanhas para conscientização de ginecologistas, coloproctologistas e gestores de saúde para a prevenção das neoplasias anais.

Várias questões ainda estão sem resposta, tais como: quais outros fatores poderiam influenciar a infecção; a evolução das mulheres nas quais foi diagnosticado o HPV em ânus; persistência ou não da detecção viral por intermédio da PCR; qual a evolução da doença anal e a incidência de neoplasias nessas pacientes; se a predominância de casos de NIC I poderia ter influenciado a falta de lesões anais por causa de subtipos virais. Outra questão em aberto é sobre os casos em que os subtipos virais não foram identificados por serem diferentes dos subtipos pesquisados (19 em ânus e 21 em colo uterino). Haveria concordância entre os subtipos virais neles? Dessa forma, ao ser encontrado valor significativo da coexistência de HPV em ânus nas mulheres com doença ginecológica HPV induzida e diante destes questionamentos ainda sem resposta, abre-se uma linha de pesquisa com o intuito 
Rev bras Coloproct

Outubro/Dezembro, 2009
Diagnóstico de HPV Anal em Mulheres com NIC:

Prevenção de Câncer do Ânus?

Alice Capobiango e Cols.
Vol. 29 de padronizar o rastreamento dessas infecções para prevenir-se o câncer de ânus.

Com o recente desenvolvimento das vacinas contra o HPV, surge perspectiva para erradicação dos cânceres anogenitais induzidos por esse vírus ${ }^{26,27}$. Essa realidade, todavia, ainda carece de mais pesquisas, pois apenas quatro subtipos de HPV são empregados na vacina $(6,11,16$ e 18.) Além disso, faz-se necessário mais tempo de seguimento da população vacinada, para avaliação da real eficácia da mesma e do custo-benefício da prevenção ${ }^{28}$.

\section{CONCLUSÕES}

Da análise dos dados deste estudo, concluiuse que:

- As mulheres com NIC têm mais probabilidade de serem acometidas por HPV anal.

- Não há concordância unânime entre os subtipos do HPV do colo do útero e do ânus.

- A paridade e o número de parceiros contribuem para aumentar a incidência de HPV anal nas mulheres sem imunodeficiência e com HPV cervical.

\begin{abstract}
This study aims were to assess the frequency of HPV anal infection in patients with cervical intra-epithelial neoplasia (CIN), to find out the relation between the found subtypes, when present in both regions, and investigate factors that influenced the occurrence of anal HPV in women with CIN. Fifty two women with age between 16 and 72 years and cervical intraepithelial neoplasia (CIN) diagnosis, grades I, II and III were studied. Material from anus and uterine cervix were obtained to identify the virus deoxyribonucleic acid (DNA) and seven virus subtypes through polymerase chain reaction (PCR). Factors that could contribute to anal infection like number of children, number of sexual partners, smoking practice, anal manipulation and intercourse, and grade of gynecologic disease were investigate. From the fifty two women, anal HPV diagnoses happened in 25 $(48 \%)$, and $23(44 \%)$ of them had HPV in uterine cervix as well; this result was significant to the presence of anal HPV in patients with CIN. In $16(31 \%)$ the HPV diagnosis occurred only in uterine cervix and in $11(21 \%)$ no HPV was detected in anus and uterine cervix. In conclusion, women with cervical intra-epihelial neoplasia have more probability to be infected with anal HPV; there is no unanimous concordance among HPV sub-types in uterine cervix and anus and the number of children and sexual partners contribute to increase the anal infection incidence in women without immuno-deficiency, with cervical HPV infection.
\end{abstract}

Key words: Human papillomavirus (HPV). Anus. Uterine cervix. Polymerase chain reaction (PCR). Intra-epithelial neoplasia (CIN).

\section{REFERÊNCIAS}

1. Nadal SR, Manzione CR. Os agentes sexualmente transmissíveis e o câncer anorretal. Rev Bras Coloproct. 2004; 24(3):274-277.

2. Nadal SR et al. Sistematização do atendimento dos portadores de infecção perianal pelo Papilomavírus Humano (HPV). Rev Bras Coloproct. 2004;24(4):322-328.

3. Sobhani I. et al. Prevalence of high-grade dysplasia and câncer in the anal canal in human papillomavirus-infected individuals. Gastroenterology. 2001;120:857-866.

4. Gonçalves MAG. et al. HPV type infection in different anogenital sites among HIV-positive Brazilian women. Infect Agents Cancer. Mar 2008; 14(3):5.

5. Hernandez BY, Mcduffie K. Anal human papillomavirus infection in women and its relashioship with cervical infection cancer. Epidemiol Biomarkers Prev. Nov 2005;14(11pt1):25506.

6. Véo CAR. et al. Study on prevalence of human papillomavirus in the anal canal of women with cervical intraepithelial neoplasia gradeIII. Eur J Obstet Gynecol Reprod Biol. Sep 2008;140(1):103-7.
7. Linhares AC, Villa LL. Vaccines against rotavirus and human papillomavirus (HPV). J Pediatr. 2000;82:S25-24.

8. Magi JC. et al. Anuscopia com exarcebação para diagnóstico de papilomavírus humano ano-retal na forma subclínica. Rev Bras Coloproct. 2002;22(3):178-183.

9. Tachezy R. et al. Human papillomavirus infection and tumours of the anal canal: correlation of histology, PCR detection in paraffin sections and serology. APMIS. Mar 2007;115(3):195-203.

10. Markos AR. The presentation of anogenital cancers as sexually transmissible infection: a case for vigilance. Sex Health. Mar 2007;4(1):79-80.

11. Monk JB, Tewari KS. The spectrum and clinical sequelae of human papillomavirus infection. Gynecologic Oncology. Nov 2007;107(2Suppl1):S6-S13.

12. Soares $\mathbf{J}$ et al. Introdução à Estatística Médica. 1.ed. Belo Horizonte: Departamento de Estatística - UFMG, 1999.

13. Scholefield JH. et al. Anal colposcopy and the diagnosis of anal intraepithelial neoplasia in high-risk gynecologic patients. Int J Gynecol Cancer. 1994;4:119-26.

14. Tavares SBN. et al. Controle da qualidade em citologia cervical: revisão da literatura. Revista Brasileira de Cancerologia. 2007;53(3):355-364. 
15. Do Carmo EFS, Fiorini A. Principais técnicas moleculares para detecção do papilomavírus humano. Sábios - Rev Saúde e Biol, Campo Mourão. Jan-Jun 2007;2(1):29-31.

16. Calore EE. et al. Expression of $\mathrm{Ki}-67$ can assist in predicting recurrences of low-grade anal intraepithelial neoplasia in AIDS. Dis Colon Rectum. 2001;44:534-537.

17. Sobit RC. et al. Detection of human papillomavirus DNA, serum $\mathrm{p} 53$, and $\mathrm{p} 53$ antibodies in patients with cervical cancer. J Environ Pathol Toxicol Oncol. 2002;21(1):79-85.

18. WHO. World Health Organization. Classification of tumours pathology and genetics of tumours of digestive system. Lyon: IARC Press, 2000.

19. Calore EE. et al. Expression of Ki-67 can assist in predicting recurrences of low-grade anal intraepithelial neoplasia in AIDS. Dis Colon Rectum. 2001; 44:534-537.

20. Burchell AN. et al. Epidemiology and transmission dynamics of genital HPV infection. Vaccine. Aug 2006;21(24;Suppl 3):S52-61, Chapter 6.

21. Gervaz P. et al. Squamous cell carcinoma of the anus: another sexually transmitted disease. Swiss Med Wkly. 2003; 133:353-9.

22. Trottier H, Franco EL. The epidemiology of genital human papillomavirus infection. Vaccine. Mar 2006;30(24 Suppl 1):S1-15.
23. Magi JC. et al. Anuscopia com exarcebação para diagnóstico de papilomavírus humano ano-retal na forma subclínica. Rev Bras Coloproct. 2002;22(3):178-183.

24. Jay N. et al. Colposcopic appearence of anal squamous intraepithelial lesions. Dis Colon Rectum. 1997;40(8):919-927.

25. Fox PA. Human papillomavirus and anal intraepitheilial neoplasia. Curr Opin Infect Dis. Feb 2006;19(1):62-6.

26. Van Doorn LJ, Kleter B, Quint WGV. Molecular detection and genotyping of Human Papillomavirus. Expert Rev Mol Diagn, 2001; 1:394-402.

27. Stanley M. Prophylactic HPV vaccines: prospects for eliminating ano-genital câncer. Br J Cancer. May 2007;7(96):1320-3.

28. Chesson HW. et al. Cost-effectiveness of human papillomavirus vaccination in the United States. Emerg Infect Dis. Feb 2008;14(2):244-51.

\section{Endereço para correspondência:}

ALICE CAPOBIANGO

Rua Paraíba 476/1.307 - Funcionários - CEP: 30130-140 -

Belo Horizonte - Minas Gerais - Brasil

Fax: (31) 32620345

E-mail: acapobiango@gmail.com 